\title{
Brown Mouse Lemurs (Microcebus rufus) May Lack Opportunities to Learn about Predator Calls
}

\author{
Anja Martha Deppe \\ School of Archaeology and Anthropology, Australian National University, \\ Canberra, ACT, Australia
}

\section{Keywords}

Antipredation behaviour - Predation - Predator recognition .

Playback experiments · Nocturnal primate

\begin{abstract}
Diurnal primates commonly modify their behaviour in response to predator vocalizations, but little is known about how nocturnal primates perceive predator calls. Mouse lemurs do not innately perceive predator calls as dangerous but may learn to do so in the wild. I hypothesized that wild brown mouse lemurs (Microcebus rufus) in Ranomafana National Park, Madagascar, differentiate between predator and non-predator vocalizations and exposed 29 adult subjects to calls of 3 sympatric predators (goshawk, fossa and owl), 3 sympatric non-predators and 4 controls. Brown mouse lemurs did not differentiate among stimuli, and there was no evidence that any recording was associated with danger, as neither activity nor spatial preferences changed in response to a stimulus, nor did subjects exhibit obvious behaviours indicative of danger such as flight or position on the branches. The failure to perceive predator calls as dangerous is common among small nocturnal solitary prey species and could be explained by a lack of learning opportunities. In social species acquired behaviours can spread quickly by social learning. Solitary species like mouse lemurs have to individually learn to associate predator calls with danger which is dependent on encounter rates. Unlike diurnal prey mouse lemurs lack the opportunity to observe diurnal raptors and associate their calls with the bird, and owls are proficient predators, which are difficult to observe in a rain forest where they hunt cryptically from perches. While sometimes nocturnal, the fossa is solitary and largely silent, and is also particularly rare at my study site. Cryptic, rare or nonvocal predators provide prey with few opportunities to associate their calls with danger. Mouse lemurs are subject to high predation rates by a wide range of predators and need to balance the costs and benefits of antipredation behaviours. Their cryptic lifestyle and
\end{abstract}

\footnotetext{
karger@karger.com www.karger.com/fp

(C) 2020 S. Karger AG, Basel
}

Karger'
Anja M. Deppe

School of Archaeology and Anthropology

Australian National University

Canberra, ACT 2600 (Australia)

anja.deppe@anu.edu.au 
preference for dense vegetation lowers the likelihood of being detected by predators, and they utilize visual and olfactory predator cues to make decisions about risk. Furthermore, their high reproductive output compensates for the high predation rates.

(c) 2020 S. Karger AG, Basel

\section{Introduction}

Predation is thought to be a major force shaping the evolution of behaviour, and for many primates it is the major cause of death [van Schaik, 1983; Cheney and Wrangham, 1987]. Behaviours such as fight that lower predation risk can however be costly [Janson and Goldsmith, 1995; Cowlishaw, 1997] and since risk is highest when a predator is nearby, an ability to detect predator presence would be beneficial. Detection can take place via sensory information provided by predators such as odour, sound and shape, and many taxa have demonstrated to varying degrees that they take advantage of such information [for reviews, see Lima and Dill, 1990; Kats and Dill, 1998; Hettena et al., 2014]. Visual detection allows for the most accurate risk assessment, but species that live in low visibility environments such as forests or are active at night should be particularly sensitive to non-visual cues. Olfactory predator recognition of mammalian predators is widespread among mammals [Kats and Dill, 1998], including some primates [e.g., Caine and Weldon, 1989; Fichtel, 2016], but due to their longevity odours rarely provide reliable information about predator proximity. Predator vocalizations may be more informative as they can reveal location and proximity. Studies however indicate that acoustic predator recognition is variable and less common among mammals and may be linked to predator densities and predator behaviour [Blumstein et al., 2008].

Many diurnal primates associate predator calls with danger, and often respond with appropriate evasion behaviours and alarm calls. For example, in response to raptor calls monkeys and lemurs descended in the canopy and scanned the sky [e.g. Sauther, 1989; Ferrari and Lopes Ferrari, 1990; Hauser and Wrangham, 1990; Macedonia and Yount, 1991; Wright, 1998; Karpanty and Grella, 2001; Searcy and Caine, 2003; Karpanty and Wright, 2007], whereas they ascended and scanned the ground in response to terrestrial predator calls [e.g. Bshary and Noe, 1997; Zuberbühler, 2000; Fichtel and Kappeler, 2002; Ouattara et al., 2009; Schel and Zuberbühler, 2009].

Comparatively little is known about how nocturnal primates utilize predator information and it has been proposed that they rely on cryptic antipredation strategies [Stanford, 2002; Miller and Treves, 2007]. Evidence however indicates that many species including tarsiers [Tarsius: Gursky, 2002, 2003], pottos [Perodicticus: CharlesDominique, 1977], galagos [Galagidae: Nash, 1986; Bearder et al., 2002) and Cheirogaleids [Schuelke, 2001; Fietz and Dausmann, 2003; Fichtel, 2016] distinguish between predators and non-predators visually and olfactorily. Studies employing predator vocalizations have been limited to lemurs and tarsiers with mixed findings. Wild spectral tarsiers (T. spectrum) responded with alarm calling to the calls of nocturnal birds of prey, wild sportive lemurs (Lepilemur spp.) sometimes looked in the appropriate direction upon hearing the call of a diurnal raptor and a mammalian predator [Karpanty and Grella, 2001; Fichtel, 2007] but wild woolly lemurs (Avahi laniger) ignored diurnal raptor calls [Karpanty and Grella, 2001]. 
Mouse lemurs (Microcebus spp.) have been studied the most, and both captiveborn and wild species perceived odours and models of predators as dangerous as indicated by flight, avoidance, vigilance and alarm calling [Deppe and Wright, 2006; Scheumann et al., 2006; Sündermann et al., 2008; Kappel et al., 2011; Rahlfs and Fichtel, 2010; Weiss et al., 2015]. Playback studies using predator vocalizations have been limited to captive-born naïve mouse lemurs which failed to distinguish between predator and non-predator calls [Bunkus et al., 2005; Scheumann et al., 2006]. This indicates that mouse lemurs do not innately associate predator calls with danger but they may learn to do so in the wild. Many taxa including birds [Curio, 1993], marsupials [Griffin et al., 2001; Griffin and Evans, 2003] and monkeys [Seyfarth and Cheney, 1980; Cook et al., 1985; Coss, 2000; Ramakrishnan and Coss, 2000; Ramakrishnan et al., 2005] have demonstrated that they acquired fear or became more discerning of predators with experience. For example, wild capuchin monkeys (Sapajus nigritus) individually learned to associate a novel sound with the image of a feared predator [Wheeler et al., 2019], and naïve rhesus monkeys (Macaca mulatta) learned to fear snakes simply from observing conspecifics being frightened [Mineka and Cook, 1988].

In this study I examined how predator-experienced mouse lemurs responded to a wide range of vocalizations. Mouse lemurs have sensitive hearing that they use to locate insect prey [Görlitz and Siemers, 2007] and during social interactions [Zimmermann and Hafen, 2001; Braune et al., 2005], and which they may employ to detect predators. I hypothesized that wild brown mouse lemurs ( $M$. rufus) differentiate between predator and non-predator calls and predicted that upon hearing a predator call they would adjust their behaviour appropriately by, for example, ascending or descending. I further predicted that mouse lemurs would alter their activity pattern after hearing a predator call because in diurnal primates and some rodents, postdetection behavioural alterations such as reduced activity can persist for hours [e.g. Abramsky et al., 1996; Bshary and Noe, 1997; Zuberbühler, 2000].

\section{Materials and Methods}

\section{Study Site, Subjects and Capture}

This study took place from April to May 2008 in the Talatakely trail system in Ranomafana National Park rain forest and the associated Centre ValBio research station in south-eastern Madagascar [Wright and Andriamihaja, 2004]. The study subject was the brown mouse lemur (M. rufus), a small nocturnal arboreal primate [Atsalis, 2008; Deppe et al., 2016] that forages solitarily for fruit and insects [Harcourt, 1987; Atsalis, 1999]. Brown mouse lemurs sleep alone on branches or in small groups in tree holes or leaf nests [Randriamiarisoa et al., 2007]. At the time of this study the brown mouse lemur population had been regularly trapped and studied for 5 consecutive years resulting in over 120 microchipped individuals.

Mouse lemurs were captured using a standard procedure employing Sherman live traps $(30 \times 8 \times 10 \mathrm{~cm})$ that were placed along the trail system 5 nights per week. For 39 nights, 30 traps were rotated among 60 trap locations at which traps were set in pairs, one trap on each side of the trail, at intervals of $25-50 \mathrm{~m}$. At 17:00 h the traps were baited with banana and fixed horizontally to vegetation up to $1.5 \mathrm{~m}$ above the ground and were recollected at 21:00 h. Mouse lemurs were taken inside their traps to the Centre ValBio research laboratory where they were weighed and identified via their microchip. They were released at their capture site within $24 \mathrm{~h}$. 
Table 1. Behavioural responses occurring during the 15-s stimulus presentation

\begin{tabular}{|c|c|c|c|c|}
\hline \multirow[t]{2}{*}{ Stimulus } & \multirow[t]{2}{*}{$n$} & \multicolumn{2}{|l|}{ Behaviours } & \multirow{2}{*}{$\begin{array}{l}\text { Responses } \\
\text { all }\end{array}$} \\
\hline & & displacement & gaze & \\
\hline Raptor & 13 & $\begin{array}{l}\text { move down (1) } \\
\text { approach speaker (2) }\end{array}$ & $\begin{array}{l}\text { look up }(1) \\
\text { look down }(2) \\
\text { look at speaker (2) }\end{array}$ & $62 \%$ \\
\hline Owl & 12 & move down (2) & $\begin{array}{l}\text { look at speaker (1) } \\
\text { scan }(2)\end{array}$ & $42 \%$ \\
\hline Fossa & 13 & move up (1) & $\begin{array}{l}\text { look down (5) } \\
\text { look up (1) }\end{array}$ & $54 \%$ \\
\hline Aye-aye & 10 & $\begin{array}{l}\text { jump sideways (1) } \\
\text { scan (5) }\end{array}$ & look at speaker (3) & $90 \%$ \\
\hline Sportive lemur & 4 & move up (1) & $\begin{array}{l}\text { look at speaker (1) } \\
\text { scan (1) }\end{array}$ & $75 \%$ \\
\hline Parrot & 5 & none & look at speaker (1) & $20 \%$ \\
\hline Dog & 4 & none & none & $0 \%$ \\
\hline Human & 3 & none & look at speaker (1) & $33 \%$ \\
\hline Cat & 3 & none & none & $0 \%$ \\
\hline Music & 10 & none & $\begin{array}{l}\text { look at speaker (3) } \\
\text { scan }(2)\end{array}$ & $50 \%$ \\
\hline
\end{tabular}

Each subject was scored for one dominant behaviour only. Predator appropriate behaviours are in bold, and the number of total behavioural responses is in percent of trials $(n)$.

\section{Playback Experiments}

Stimuli

In each trial I presented one of the following 10 stimuli (Table 1): vocalizations from known mouse lemur predators [Goodman et al., 1993; Goodman, 2003] were (1) the Henst's goshawk (Accipiter henstii), (2) the fossa (Cryptoprocta ferox) and (3) the Madagascar long-eared owl (Asio madagascariensis). Non-predator vocalizations were from 3 sympatric species: (4) the aye-aye (Daubentonia madagascariensis), (5) the weasel sportive lemur (Lepilemur mustelinus) and (6) the vasa parrot (Caracopsis nigra), as well as 2 potentially familiar sounds, i.e. (7) a local dog (sometimes heard from the park edge) and (8) human conversation (tourists and research). Novel sounds were (9) country music and (10) a cat meowing (there were no feral cats, and only one indoor pet cat $7 \mathrm{~km}$ away). Recordings were provided by Marina Scheumann and Elke Zimmermann at the Technische Hochschule in Hannover, Germany, except for Henst's goshawk and the aye-aye which were obtained from the Macaulay Library of Sounds (www.macaulaylibrary.org).

\section{Experimental Procedure}

Experiments took place between 22:00 and 2:00 $\mathrm{h}$ in a wire mesh cage $(1.5 \times 1 \times 1 \mathrm{~m})$ fitted with guava branches (Fig. 1). The cage had one large door $(50 \times 50 \mathrm{~cm})$ for general access and a small door $(10 \times 12 \mathrm{~cm})$ through which a Sherman trap could be placed to release or recapture a mouse lemur. The cage was placed at a wall under a small roof outside the research lab across from the forest edge and the river. The cage top was covered and a black curtain with viewing slits hid two observers that sat $1.5 \mathrm{~m}$ away from the cage. Stimuli were broadcast via two Hama speakers $(10 \times 5 \mathrm{~cm}$, frequency output range between $20 \mathrm{~Hz}$ and $20 \mathrm{kHz}$ ) from a laptop computer (HP $\mathrm{z} 4114)$. The speakers were attached next to each other in the front top corner of the cage and sound files were played at full volume. Trials took place under natural night time illumination plus some faint residual light from the upper levels of the research station and a red light above 
Fig. 1. The cage and location where the experiment took place $(1.5 \times 1 \times 1 \mathrm{~m})$. It was furnished with guava branches.

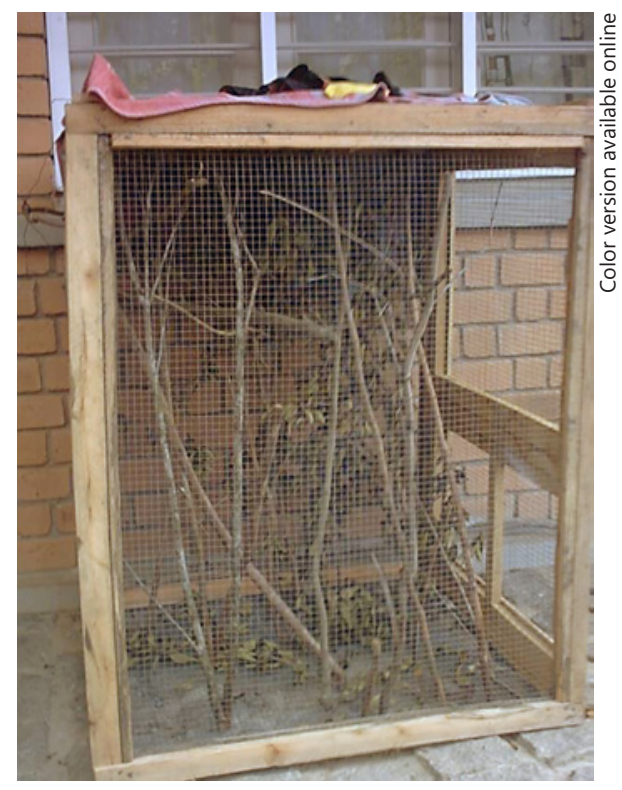

the cage. While trials were recorded with an infra-red video camcorder, these proved useless as the light reflected from the metal mesh and branches obscured behaviour.

I tested a total of 29 known microchipped adult mouse lemurs that had been captured in the hours preceding trials, and which remained in their traps inside the lab for up to $4 \mathrm{~h}$ prior to testing. Subjects received fresh fruit and water while waiting. Preceding the first experimental trial, each subject received $\mathrm{a}>3-\mathrm{h}$ habituation trial in the cage and prior to each experimental trial, a subject was allowed to habituate to the cage for $30 \mathrm{~min}$. All subjects were used to trapping and handling, and started exploring the cage within minutes. There were a total of 77 trials, each lasting 12\%/4 min: a 15-s stimulus presentation was preceded and followed by 6 stimulus-free minutes. Each subject was tested separately, received only one trial per night consisting of a single stimulus and was presented only once with a stimulus to avoid habituation.

\section{Variables Measured}

During the 6 min preceding and following the presentation of the stimulus, a subject's location and behaviour were recorded every $15 \mathrm{~s}$ (continuous observation was difficult, so this allowed time to locate the subject). To assess whether subjects changed their general behaviour after a playback had ceased, I recorded 3 spatial and 1 behavioural category to establish pre- and poststimulus activity patterns in each individual: (1) height within the cage (top, middle, bottom), (2) front (speaker side) or back of the cage, (3) left or right of the cage as viewed from the front, and (4) subject is motionless or moving. Additional behaviours recorded included gaze, jumping and scanning. During the 15-s stimulus presentation, behaviour was recorded ad libitum.

\section{Data Analysis}

To determine whether a stimulus induced a significant change in behaviour or spatial preferences I compared their frequencies before and after the 15-s stimulus presentation within each trial. For each trial the 4 categories were separated. Within each category there were two states (for example front/back) except for height, which had three (top, middle or bottom). Within each of the three categories with two states, I calculated the number of occurrences for each state for the "before" period of a trial. Since there were 25 data points $(6 \mathrm{~min} / 15 \mathrm{~s}=25)$, the state that occurred a minimum of 13 times $(>50 \%)$ was declared the dominant state which I compared to the 
same state's occurrence in the "after" period. For example, if front occurred 14 times before and once after, the absolute change score (ACS) was 13 (14-1), and it was irrelevant whether the ACS was positive or negative.

This ACS adequately quantified both drastic and very little change in behaviour but not intermediate changes (moderately active subjects). For example, an overall motionless subject that changed its location from the front to the back of the cage right after the playback and stayed there, received the maximum ACS of 25 (e.g. [front before $=25$ ] - [front after $=0$ ] =25). A very active animal that became and remained motionless right after hearing the stimulus received a much lower ACS (e.g. [front before = 14] - [front after 1] =13), even though the behavioural change is equivalent to the former if not more drastic. To account for this I converted ACS into percent change scores (PCS) by calculating the highest possible change available to the subject in that trial: in the first example the maximum change possible was 25 (going from 25 occurrences of front to $0=100 \%$ change) and in the second example it would be 14 (going from 14 occurrences to $0=100 \%$ change). I calculated the PCS by dividing the ACS by the maximum change possible, so in the latter example the percent change was $(\mathrm{ACS}=13) / 14 \times 100=92.9 \%$. The PCS allowed to quantify the change within each trial taking into account a subject's overall activity and location preferences.

With this method it made no difference where a subject was or what it did; it only mattered if a given pattern changed after the stimulus presentation. I applied the above calculations to each trial in all three 2-state categories and modified it slightly to accommodate the 3-state height category by calculating a general change score: each height change was a 1 score, which meant that the more a subject moved up and down, the higher the change score. Again, I compared the change score before to after within each trial, and using the same above equations, I calculated the ASC and the PCS. I applied one-way (factor) ANOVAs followed by Fisher's PLSD post hoc tests to compare both the ACS and the PCS separately amongst the 10 stimuli. To compare the frequency of behavioural responses among the different stimuli and subgroups (predator, nonpredator, novel), I applied a Fisher exact test with an $\alpha$-level set at 0.05 .

\section{Results}

Depending on capture frequency each subject was exposed to at least 1 predator and 1 non-predator stimulus (average number of trials 2.59, range 2-6). Subjects did not significantly change their activity pattern or spatial preferences after hearing a stimulus: change score comparisons were uniformly non-significant, for both the ACS: height $(F[9,67]=0.47, p=0.89)$, front $/$ back $(F[9,67]=0.93, p=0.50)$, left $/$ right $(F[9,67]=0.29, p=0.97)$ and behaviour $(F[9,67]=0.72, p=0.68)$, and the PCS: height $(F[9,67]=0.47, p=0.89)$, front/back $(F[9,67]=0.88, p=0.54)$, left $/$ right $(F[9,67]=0.51, p=0.86)$ and behaviour $(F[9,67]=0.59, p=0.80)$. When analysing the frequency of (any) behavioural responses during the stimulus playback, all comparisons were non-significant (Table 1): all three predators versus all other stimuli $(p<0.05)$, sympatric non-predators (lemurs and parrot) versus controls $(p<0.05)$, predators versus sympatric species (lemurs and parrot) $(p<0.05)$, as well as among the three predators $(p<0.05)$. However, behavioural responses occurred more often in response to familiar than unfamiliar sounds $(p=0.058)$.

\section{Discussion}

Brown mouse lemurs did not distinguish between stimuli, and none elicited any obvious behavioural change. Subjects that were active prior to stimulus presentation remained active after hearing a stimulus and ones that were less active maintained 
that pattern. A lack of reaction does not necessarily imply that stimuli were meaningless but instead may have not been perceived as dangerous in the context of the experiment. For example, being inside the cage may have heightened the perception of safety [Searcy and Caine, 2003], or perhaps subjects were distracted or not habituated enough to pay attention to the recordings. Frightened or stressed mouse lemurs tend to freeze up for long periods of time (pers. observation) and there was no evidence of this as the subjects moved around, ate fruit and captured insects while in the cage. Also, shorter habituation times in a novel enclosure did not prevent brown mouse lemurs from exhibiting flight, jumping and bipedality in response to visual and olfactory predator stimuli [Deppe, 2005; Deppe and Wright, 2006]. While there were methodological limitations, especially the difficulty of detecting subtle behaviours, I instead argue that my findings could be explained by a lack of opportunities to learn about raptor, owl and fossa calls.

When learning is necessary, prey will benefit from sharing their activity period with a predator as this allows prey to learn from observation. Wheeler et al. [2019] showed that once capuchin monkeys had associated a sound with danger it persisted for at least 2 years. In social species an individually acquired association can spread quickly via social learning. Species that are solitary depend much more on learning from personal experience.

This can explain why many diurnal social, but also diurnal solitary species, including rodents [for review, see Blumstein et al., 2002] and primates [e.g. Sauther, 1989; Ferrari and Lopes Ferrari, 1990; Zuberbühler, 2000] associated diurnal raptor calls with danger. Nocturnal species on the other hand sleep while diurnal raptors are active. This lack of observational opportunities might explain why nocturnal rodents and marsupials [ Blumstein et al., 2008; Hettena et al., 2014], woolly lemurs [Karpanty and Grella, 2001], spectral tarsiers [Gursky, 2002] as well as my mouse lemur subjects did not associate diurnal avian predator calls with danger. The reason why nocturnal sportive lemurs were wary when hearing a diurnal raptor call [Karpanty and Grella, 2001; Fichtel, 2007] might be found in their habit of taking sunbaths during the day which allows them to observe raptors.

The Madagascar long-eared owl shares its activity period with mouse lemurs, and thus associative learning is potentially possible. However, in forests this owl hunts cryptically from perches so while a mouse lemur might pass by a vocalizing owl, it may not survive this encounter as owls have a hunting success rate of up to $75 \%$ [Vermeij, 1982]. Even mice, rats and gerbils that are preyed upon by owls that hunt from the sky like a diurnal raptor did not associate owl calls with danger [Hettena et al., 2014; but see Abramsky et al., 1996]. The reason why owls have a high hunting success and often are the highest threat to small nocturnal mammals, including mouse lemurs [Goodman et al., 1991], is probably because they do not provide many early warning cues: they fly silently and can hunt in total darkness [Payne, 1971; Konishi, 1973] and birds may not provide sufficient odour cues. This explains why mouse lemurs did not perceive owl models or odour as threatening [Deppe, 2005; Deppe and Wright, 2007; Kappel et al., 2011]. The notable exception was the spectral tarsier [Gursky, 2002] which responded with behavioural change and alarm calling to calls of nocturnal predatory birds including an owl. Responses were already exhibited by very young infants suggesting that call recognition may be innate and does not require learning.

The mammalian predator I used was the fossa, a solitary feline-like viverrid that is active both night and day [Dollar et al., 2007]. Comparatively few studies have used 
mammalian predator calls, and most involved diurnal social prey species that have the advantage of social learning [Hettena et al., 2014]. Solitary species have to rely on personal experience, and when predators are rare or silent there are few associative learning opportunities. The fossa is only vocal during its mating season [Dollar et al., 2007] and at my study site it is particularly rare, which might explain why my subjects had not learned to associate calls with danger. Mule deer (Odocoileus hemionus) likewise ignored the call of the silent, solitary mountain lion but did associate calls of the social and vocal wolf calls with danger [Hettena et al., 2014]. In other locations mouse lemurs may react differently, for example, at the dry-forest site at Kirindy where diurnal lemurs (Eulemur rufifrons and Propithecus verreauxi) sometimes alarm called and fled when hearing either a fossa call or a dog bark [Fichtel and Kappeler, 2002]. However, visibility is higher in a dry than a rain forest and at Kirindy, there is a relatively high density of feral dogs and fossa, which could also explain why 4 of 7 redtailed sportive lemurs moved when hearing the fossa [Fichtel, 2007]. Furthermore, diurnal lemurs and sportive lemurs may be targeted by fossa resulting in encounter rates and associative learning opportunities. Scat analysis revealed that fossa rarely eat mouse lemurs [Hawkins, 2003], probably because the small branch niche that mouse lemurs prefer cannot support the fossa's weight.

In conclusion, small animals such as mouse lemurs that suffer high predation rates by a wide range of predators need to balance the costs and benefits of antipredation behaviours. To compensate for high predation rates, mouse lemurs have a high reproductive output of up to two litters per year [Blanco, 2008]. Being small and solitary, mouse lemurs are inconspicuous and their preference for dense vegetation reduces the probability of being detected by predatory birds and mammalian predators. While social diurnal prey species often associate predator calls with danger, most nocturnal ones do not [Hettena et al., 2014]. Nocturnal species tend to be solitary and thus depend on individual learning which is influenced by predator density, vocalization frequency and shared activity periods. Moreover, predator vocalizations may not be reliable indicators of predator proximity because predators on the hunt tend to be silent, and in a dense forest sounds can be distorted [Waser and Brown, 1986].

\section{Acknowledgements}

I thank the Institute for the Conservation of Tropical Environments (ICTE/MICET), Madagascar National Parks (MNP), and the Malagasy Ministère des Eaux et Forêts (CAFF/CORE). This project would not have been possible without the support of the staff at the Centre ValBio Research Station, in particular Anna Feistner and my research technician Rasendrinirina Victor. I especially thank my $\mathrm{PhD}$ advisor Patricia Wright, Misa Randriamiarisoa, Marina Blanco, and my volunteers Hannah Thomas and Louise Reynolds for their help, and John Robinson at Sony Brook University for his help with experimental design and data analysis. Many thanks go to Marina Scheumann and Elke Zimmermann for allowing me to use their sound files, and to the anonymous reviewers who helped improve this manuscript.

\section{Statement of Ethics}

All protocols were approved by and are in compliance with the Stony Brook University Institutional Animal Care and Use Committee (IACUC \#2008-1597) and the rules and regulations of Madagascar. No animals were harmed as a result of this study. 


\section{Disclosure Statement}

I understand the Folia Primatologica declaration of interest and declare that I have no competing interests.

\section{Funding Sources}

Funding was provided by Primate Conservation Inc., Conservation International, Stony Brook University and the National Science Foundation (grants 0726166 and 0721233).

\section{References}

Abramsky Z, Strauss E, Subach A, Riechman A, Kotler BP (1996). The effect of barn owls (Tyto alba) on the activity and microhabitat selection of Gerbillus allenbyi and G. pyramidum. Oecologica 105: 313-319.

Atsalis S (1999). Diet of the brown mouse lemur (Microcebus rufus) at Ranomafana National Park, Madagascar. International Journal of Primatology 20: 193-229.

Atsalis S (2008). A Natural History of the Brown Mouse Lemur. Upper Saddle River, Pearson Prentice Hall.

Bearder S, Nekaris KA, Buzell A (2002). Dangers in the night: are some nocturnal primates afraid of the dark? In Eat or Be Eaten: Predator Sensitive Foraging among Primates (Miller LE, ed.), pp 21-43. Cambridge, Cambridge University Press.

Blanco MB (2008). Reproductive schedules of female Microcebus rufus at Ranomafana National Park, Madagascar. International Journal of Primatology 29: 323-338.

Blumstein DT, Cooley L, Winternitz J, Daniel JC (2008). Do yellow-bellied marmots respond to predator vocalizations? Behavioral Ecology and Social Biology 62: 457-468.

Blumstein DT, Mari M, Daniel JC, Ardron JG, Griffin AS, Evans CS (2002). Olfactory predator recognition: wallabies may have to learn to be wary. Animal Conservation 5: 87-93.

Braune P, Schmidt S, Zimmermann E (2005). Spacing and group coordination in a nocturnal primate, the golden brown mouse lemur (Microcebus ravelobensis): the role of olfactory and acoustic signals. Behavioural Ecology and Sociobiology 58: 587-596.

Bshary R, Noe R (1997). Anti-predation behaviour of red colobus monkeys in the presence of chimpanzees. Behavioural Ecology and Sociobiology 41: 321-333.

Bunkus E, Scheumann M, Zimmermann E (2005). Do captive-born grey mouse lemurs (Microcebus murinus) recognize their natural predators by acoustic cues? Primate Report 72: 22.

Caine NG, Weldon PJ (1989). Responses by red-bellied tamarins (Saguinus labiatus) to fecal scents of predatory and non-predatory Neotropical mammals. Biotropica 21: 186-189.

Charles-Dominique P (1977). Ecology and Behaviour of Nocturnal Primates, p 277. New York, Columbia University Press.

Cheney DL, Wrangham RW (1987). Predation. In Primate Societies (Smuts BB, Cheney RM, Seyfarth RM, Wrangham RW, Struhsaker TT, eds.), pp 227-239. Chicago, University of Chicago Press.

Cook M, Mineka S, Wolkenstein B, Laitsch K (1985). Observational conditioning of snake fear in unrelated rhesus monkeys. Journal of Abnormal Psychology 94: 591-610.

Coss R, Ramakrishnan U (2000). Perceptual aspects of leopard recognition by wild bonnet macaques (Macaca radiata). Behaviour 137: 315-335.

Cowlishaw GC (1997). Trade-offs between foraging and predation risk determine habitat use in a desert baboon population. Animal Behaviour 53: 667-686.

Curio E (1993). Proximate and developmental aspects of antipredator behavior. Advances in the Study of Behavior 22: 135-238.

Deppe AM (2005). Visual predator recognition and response in wild brown mouse lemurs (Microcebus rufus) in Ranomafana National Park, Madagascar. American Journal of Primatology 66 (suppl 1): 97-98.

Deppe AM, Wright PC (2006). Visual and olfactory snake recognition in wild brown mouse lemurs (Microcebus rufus). Primate Report 73: 12.

Deppe AM, Wright PC (2007). Owl recognition via visual, olfactory and auditory sensory cues in a small nocturnal primate, Microcebus rufus, in Ranomafana National Park, Madagascar. International Prosimian Congress, Ithala, South Africa. 
Deppe AM, Baden A, Wright PC (2016). The effects of the lunar cycle, rainfall, and temperature on trapping success in the brown mouse lemur (Microcebus rufus) in Ranomafana National Park, Madagascar. In The Dwarf and Mouse Lemurs of Madagascar: Biology, Behaviour, and Conservation Biogeography of the Cheirogaleidae (Lehman S, Radespiel E, Zimmermann E, eds.), pp 195-209. Cambridge, Cambridge University Press.

Dollar L, Ganzhorn JU, Goodman SM (2007). Primates and other prey in the seasonally variable diet of Cryptoprocta ferox in the dry deciduous forest on western Madagascar. In Primate Anti-Predator Strategies (Gursky S, Nekaris KAI, eds.), pp 63-76. New York, Springer.

Ferrari SF, Lopes Ferrari MAL (1990). Predator avoidance behaviour in the buffy-headed marmoset, Callithrix flaviceps. Primates 31: 323-338.

Fichtel C (2007). Avoiding predators at night: antipredator strategies in red-tailed sportive lemurs (Lepilemur ruficaudatus). American Journal of Primatology 69: 611-624.

Fichtel C (2016). Predation in the dark: antipredator strategies of Cheirogaleidae and other nocturnal primates. In The Dwarf and Mouse Lemurs of Madagascar: Biology, Behaviour, and Conservation Biogeography of the Cheirogaleidae (Lehman S, Radespiel E, Zimmermann E, eds.), pp 366-380. Cambridge, Cambridge University Press.

Fichtel C, Kappeler P (2002). Anti-predator behaviour of group-living Malagasy primates: Mixed evidence for a referential alarm call system. Behavioural Ecology and Sociobiology 52: 262-275.

Fietz J, Dausmann KH (2003). Costs and potential benefits of parental care in the nocturnal fat-tailed dwarf lemur (Cheirogaleus medius). Folia Primatologica 74: 246-258.

Goodman SM (2003). Predation on lemurs. In The Natural History of Madagascar (Goodman SM, Benstead JP, eds.), pp 1221-1228. Chicago, University of Chicago Press.

Goodman SM, Creighton GK, Raxworthy C (1991). The food habits of the Madagascar long-eared owl Asio madagascariensis in southeastern Madagascar. Bonner Zoologische Beitraege 42: 21-26.

Goodman SM, O'Connor S, Langrand O (1993). A review of predation on lemurs: implications for the evolution of social behaviour in small, nocturnal primates. In Lemur Social Systems and Their Ecological Basis (Kappeler PM, Ganzhorn JU, eds.), pp 51-66. New York, Plenum Press.

Görlitz H, Siemers BM (2007). Sensory ecology of prey rustling sounds: acoustical features and their classification by wild Grey Mouse Lemurs. Functional Ecology 21: 143-153.

Griffin AS, Evans CS (2003). Social learning of antipredator behaviour in a marsupial. Animal Behaviour 66: 485-492.

Griffin AS, Evans CS, Blumstein DT (2001). Learning specificity in acquired predator recognition. Animal Behaviour 62: 577-589.

Gursky S (2002). The behavioral ecology of the spectral tarsier, Tarsius spectrum. Evolutionary Anthropology 11: 226-234.

Gursky S (2003). Predation experiments with infant spectral tarsiers (Tarsius spectrum). Folia Primatologica $74: 272-284$.

Harcourt C (1987). Brief trap/retrap study of the brown mouse lemur (Microcebus rufus). Folia Primatologica 49: 209-211.

Hauser MD, Wrangham RW (1990). Recognition of predator and competitor calls in nonhuman primates and birds: a preliminary report. Ethology 86: 116-130.

Hawkins CE (2003). Cryptoprocta ferox, Fossa, Fossa. In The Natural History of Madagascar (Goodman SM, Benstead JP, eds.), pp 1360-1363. Chicago, University of Chicago Press.

Hettena AM, Munoz N, Blumstein DT (2014). Prey responses to predator's sounds: a review and empirical study. Ethology 120: 427-452.

Janson C, Goldsmith M (1995). Predicting group size in primates: foraging costs and predation risks. Behavioural Ecology 63: 326-336.

Kappel P, Hohenbrinck S, Radespiel U (2011). Experimental evidence for olfactory predator recognition in a wild mouse lemur. American Journal of Primatology 73: 928-938.

Karpanty S (2006). Direct and indirect impacts of raptor predation on lemurs in southeastern Madagascar. International Journal of Primatology 27: 239-261.

Karpanty S, Grella R (2001). Lemur responses to diurnal raptor calls in Ranomafana National Park, Madagascar. Folia Primatologica 72: 100-103.

Karpanty SM, Wright PC (2007). Predation on lemurs in the rainforest of Madagascar by multiple predator species: observations and experiments. In Primate Anti-Predator Strategies (Gursky S, Nekaris KAI, eds.), pp 77-99. New York, Springer.

Kats LB, Dill LM (1998). The scent of death: chemosensory assessment of predation by prey animals. Écoscience 5: 361-394.

Konishi M (1973). Locatable and nonlocatable acoustic signals for barn owls. The American Naturalist 107: 775-785.

Lima SL, Dill LM (1990). Behavioural decisions made under the risk of predation: a review and prospectus. Canadian Journal of Zoology 68: 619-640. 
Macedonia JM, Yount PL (1991). Auditory assessment of avian predator threat in semi-captive ringtailed lemurs (Lemur catta). Primates 32: 169-182.

Mineka S, Cook M (1988). Social learning and the acquisition of snake fear in monkeys. In Social Learning: Psychological and Biological Perspectives (Zentall TR, Galef BG, eds.), pp 51-73, Hillsdale, Lawrence Erlbaum Associates.

Miller LE, Treves A (2007). Predation on primates. In Primates in Perspective (Campbell CJ, Fuentes A, MacKinnon KC, Panger M, Bearder SK, eds.), pp 525-543, New York, Oxford University Press.

Nash L (1986). Influence of moonlight levels on traveling and calling patterns in two sympatric species of Galago in Kenya. In Current Perspectives in Primate Social Dynamics (Taub D, King F, eds.), pp 357-367. New York, Van Norstrand Reinhold.

Ouattara K, Lemasson A, Zuberbühler K (2009). Anti-predator strategies of free-ranging Campbell's monkeys. Behaviour 146: 1687-1708.

Payne RS (1971). Acoustic location of prey by barn owls (Tyto alba). Journal of Experimental Biology 54: 535-573.

Rahlfs M, Fichtel C (2010). Anti-predator behavior in a nocturnal primate, the grey mouse lemur (Microcebus murinus). Ethology 116: 429-439.

Randriamiarisoa M, Deppe AM, Wright PC (2007). Sleeping group and sleeping site characteristics in a small nocturnal rain forest primate, the brown mouse lemur Microcebus rufus in Ranomafana National Park, Madagascar. International Prosimian Congress, Ithala, South Africa. Conference Proceedings.

Ramakrishnan U, Coss R (2000). Age differences in the response to adult and juvenile alarm calls by bonnet macaques (Macaca radiata). Ethology 106: 131-144.

Ramakrishnan U, Coss RG, Schank J, Dharawat A, Kim S (2005). Snake species discrimination by wild bonnet macaques (Macaca radiata). Ethology 111: 337-356.

Sauther ML (1989). Antipredator behaviour in troops of free-ranging Lemur catta at Beza Mahafaly Special Reserve, Madagascar. International Journal of Primatology 10: 595-606.

Schel AM, Zuberbühler K (2009). Responses to leopards are independent of experience in guereza colobus monkeys. Behaviour 146: 1709-1737.

Scheumann M, Bunkus E, Sündermann D, Zimmermann E (2006). Acoustic and olfactory predator recognition in predator-naive grey mouse lemurs (Microcebus murinus). International Journal of Primatology 27: 88.

Schuelke O (2001). Social anti-predator behavior in a nocturnal lemur. Folia Primatologica 72: 332-334.

Searcy YM, Caine NG (2003). Hawk calls elicit alarm and defensive reactions in captive Geoffroy's marmosets (Callithrix geoffroyi). Folia Primatologica 74: 115-125.

Seyfarth RM, Cheney DL (1980). The ontogeny of vervet alarm calling behaviour: a preliminary report. Zeitschrift für Tierpsychologie 54: 37-56.

Stanford CB (2002). Avoiding predators: expectations and evidence in primate anti-predator behaviour. International Journal of Primatology 23: 741-758.

Sündermann D, Scheumann M, Zimmermann E (2008). Olfactory predator recognition in predator-naive gray mouse lemurs (Microcebus murinus). Journal of Comparative Psychology 122: 146-155.

Van Schaik CP (1983). Why are diurnal primates living in groups? Behaviour 87: 120-144.

Vermeij GJ (1982). Unsuccessful predation and evolution. The American Naturalist 120: 701-720.

Waser PM, Brown CH (1986). Habitat acoustics and primate communication. American Journal of Primatology 10: 135-154.

Weiss L, Brandl P, Frynta D (2015). Fear reactions to snakes in naïve mouse lemurs and pig-tailed macaques. Primates 56: 279-284.

Wheeler BC, Fahy M, Tiddi B (2019). Experimental evidence for heterospecific alarm signal recognition via associative learning in wild capuchin monkeys. Animal Cognition 22: 687-695.

Wright PC (1998). Impact of predation risk on the behaviour of Propithecus diadema edwardsi in the rain forest of Madagascar. Behaviour 135: 483-512.

Wright PC, Andriamihaja B (2004). Making a rainforest national park work in Madagascar: Ranomafana National Park and its long-term research commitment. In Making Parks Work: Strategies for Preserving Tropical Environments (Terborgh J, van Schaik CP, Davenport L, Rao M, eds.), pp 112-136. Covelo, Nature Island Press.

Zimmermann E, Hafen TG (2001). Colony specificity in a social call of mouse lemurs (Microcebus ssp.). American Journal of Primatology 54: 129-141.

Zuberbühler K (2000). Casual knowledge of predator behaviour in wild Diana monkeys. Animal Behaviour 59: 209-220. 